\title{
STUDY OF OCULAR INJURIES IN ROAD TRAFFIC ACCIDENT PATIENTS
}

\author{
Elangovan Marudhamuthu' ${ }^{1}$, N. Sivakumar'2, T. Kumaravel ${ }^{3}$
}

1 Professor, Department of Ophthalmology, Government Dharmapuri Medical College and Hospital, Dharmapuri.

${ }^{2}$ Associate Professor, Department of Ophthalmology, Government Dharmapuri Medical College and Hospital, Dharmapuri.

${ }^{3}$ Assistant Professor, Department of Ophthalmology, Government Dharmapuri Medical College and Hospital, Dharmapuri.

\begin{abstract}
\section{BACKGROUND}

The purpose of the study is to analyse the ocular manifestations in Road Traffic Accidents (RTA) and to find the incidence of ocular injury in RTA and causes of decreased vision related to RTA. The study was conducted in Government. Dharmapuri Medical College Hospital, Dharmapuri, Tamilnadu. Patients referred from Trauma/Surgical wards to Ophthalmic outpatient department and patients examined in Trauma Ward for Ophthalmology opinion in RTA injuries were analysed.

Aim- The aim of the study is to find out the ocular findings in Road Traffic Accident patients and analyse the impact of RTA in ocular morbidity.
\end{abstract}

\section{MATERIALS AND METHODS}

Patients with ocular and periocular injuries underwent complete ocular examination including visual acuity, anterior segment examination by torch light to access pupillary action, slit-lamp examination and posterior segment examination by $78 \mathrm{D}$ Lens or Indirect ophthalmoscope using 20 D lens. Patients with suspected posterior globe rupture underwent USG B-Scan and CT Orbit.

\section{RESULTS}

In the study, Males (85.33\%) had more injuries when compared to Females (14.67\%). Persons driving two wheelers (87.33\%) were more prone to ocular injuries when compared to pedestrians and persons travelling in auto and four wheelers. Driving without helmets (92\%) and driving under the influence of alcohol (78\%) were found to be common in ocular injuries. Closed globe injury (95.34\%) was more common than open globe injury. Common causes for decreased vision associated with ocular injuries are Traumatic optic neuropathy, Ruptured Globe, Commotio Retinae, Corneal laceration, Hyphaema, Iridocyclitis, Lens injury and Vitreous Haemorrhage.

\section{CONCLUSION}

Ocular trauma is a major cause of preventable monocular blindness and visual impairment in the world. It is the cause of blindness or partial loss of vision in more than half a million people worldwide. Almost $75 \%$ of people with trauma become blind (monocular). Blindness results from Phthisis bulbi, Corneal scars, Hyphaema, Cataract, Retinal detachment, Macular scar and Optic neuropathy. The fact that appropriate treatment in a tertiary care centre did not significantly influence the final visual outcome makes it imperative that preventive eye care programs for the travelling population is of utmost priority. Public health education aimed at increasing awareness in the travelling public especially for vulnerable groups and stopping drunken driving is urgently needed in order to reduce ocular morbidity due to ocular trauma.(1)

\section{KEYWORDS}

Road Traffic Accidents, Ocular and Periocular Injuries, Visual Acuity.

HOW TO CITE THIS ARTICLE: Marudhamuthu E, Sivakumar N, Kumaravel T. Study of ocular injuries in road traffic accident patients. J. Evolution Med. Dent. Sci. 2017;6(41):3219-3222, DOI: 10.14260/Jemds/2017/697

\section{BACKGROUND}

There is a phenomenal increase in the number of Road Traffic Accidents (RTA) in our country of late. There is a spurt in the number of vehicles occupying the road and the number of new drivers also increasing. With the increase in Road Traffic Accidents, the injuries to humans vary from mild to severe including injury to eyes.

The Eye injuries vary from very simple to severe injuries. In addition, eye injuries create a lot of panic to the suffering patients.

Financial or Other, Competing Interest: None.

Submission 24-03-2017, Peer Review 05-05-2017,

Acceptance 15-05-2017, Published 22-05-2017.

Corresponding Author:

Elangovan Marudhamuthu,

Professor, Department of Ophthalmology,

Government Dharmapuri Medical College and Hospital,

Dharmapuri-636701. Tamilnadu, India.

E-mail: malarelangovan80@gmail.com

DOI: $10.14260 /$ jemds $/ 2017 / 697$
Severe eye injuries cause a long-lasting disability causing vision loss as well as financial loss to the person and his/her family. Hence, prevention of eye injuries and thereby saving the victim from the disability and stress is the need of the hour.

The lifetime prevalence of ocular trauma is higher than that of diseases like glaucoma, age-related macular degeneration or diabetic retinopathy.(2)

Out of all types of ocular emergencies, ocular trauma is by far the commonest, constituting nearly $75 \%$ of all ocular emergencies.(3)

In Road Traffic Accidents, any area of the eye may be injured. The injury may involve the anterior structures like eyelids, conjunctiva, cornea, sclera or lacrimal apparatus. It may involve deeper structures like uvea, lens or extraocular muscles. It may also involve posterior structures like vitreous, choroid, retina or optic nerve avulsion. It may also cause gross injury like ruptured globe or surrounding injury like orbital fracture. 


\section{Terminology}

- Closed injury is commonly due to blunt trauma. The corneoscleral wall of the globe is intact.

- Open injury involves a full-thickness wound of the corneoscleral envelope.

- Contusion is a closed injury resulting from blunt trauma. Damage may occur at or away from the site of impact.

- Rupture is a full-thickness wound caused by blunt trauma. The globe gives way at its weakest point, which may not be at the site of impact.

- Laceration is a full-thickness defect in the eye wall produced by a tearing injury, usually as the result of a direct impact.

- Lamellar laceration is a partial-thickness laceration.

- Incised injury is caused by a sharp object such as glass or a knife.

- Penetrating injury refers to a single full-thickness wound, usually caused by a sharp object, without an exit wound. A penetrating injury may be associated with intraocular retention of a foreign body.

- Perforation consists of two full-thickness wounds, one entry and one exit, usually caused by a missile.

The Ocular Trauma Classification Group has attempted to develop a uniform classification system for mechanical injuries to the eye, based on primary evaluation. Injuries are broadly divided into two categories-

1. Open-globe-full-thickness defects in the corneoscleral coat of the eye; and

2. Closed-globe-ocular injury without a full-thickness defect of the coats.

In both the categories the injuries are graded from the anterior segment backwards. The injury is further graded with regard to visual acuity and the presence or absence of an afferent papillary defect.

\begin{tabular}{|c|c|}
\hline \multicolumn{2}{|r|}{ Ophthalmic Effects of Injury } \\
\hline $\begin{array}{c}\text { Ocular tissue } \\
\text { involved }\end{array}$ & Clinical manifestations \\
\hline Orbit & $\begin{array}{l}\text { Blow-out fracture of medial wall or floor, } \\
\text { Orbital haematoma, Carotid-cavernous fistula }\end{array}$ \\
\hline Eyelids & Haematoma, Avulsion of the lower lid \\
\hline Conjunctiva & Subconjunctival Haemorrhage \\
\hline Anterior uvea & $\begin{array}{l}\text { Hyphaema, Tears of the iris sphincter and } \\
\text { iridodialysis, Angle recession and } \\
\text { cyclodialysis }\end{array}$ \\
\hline Lens & $\begin{array}{l}\text { Rosette cataract, Subluxation of the lens, } \\
\text { Rupture of the anterior or posterior capsule }\end{array}$ \\
\hline Sclera & $\begin{array}{l}\text { Rupture, commonly at the limbus or behind } \\
\text { the insertion of the recti }\end{array}$ \\
\hline Vitreous & Haemorrhage \\
\hline Choroid & $\begin{array}{c}\text { Choroidal rupture, Suprachoroidal } \\
\text { haemorrhage }\end{array}$ \\
\hline Retina & $\begin{array}{l}\text { Retinal or subretinal haemorrhage, Retinal } \\
\text { oedema, commotio retinae, Retinal dialysis, } \\
\text { Macular oedema or hole }\end{array}$ \\
\hline Optic nerve & $\begin{array}{l}\text { Optic nerve avulsion, Haemorrhage of the } \\
\text { optic nerve sheath }\end{array}$ \\
\hline & Table 1 \\
\hline
\end{tabular}

Orbital trauma can damage both the facial bones and adjacent soft tissues. An intraocular examination must always be performed in patients with orbital trauma.
Ocular damage associated with orbital trauma include hyphaema, angle recession, corneoscleral laceration, Retinal Dialysis and Vitreous Haemorrhage.

\section{Investigations}

- Ultrasonography B Scan- may be useful in the detection of intraocular foreign bodies, globe rupture, suprachoroidal haemorrhage and retinal detachment.

- $\quad$ Plain radiographs.

- $\quad$ CT is superior to plain radiography in the detection and localisation of intraocular foreign bodies. It is also of value in determining the integrity of intracranial, facial and intraocular structures.

- MRI is more accurate than CT scan in the detection and assessment of injuries of the globe itself such as an occult posterior rupture, However MRI should not be performed if a ferrous metallic foreign body is suspected.

\section{MATERIALS AND METHODS}

\section{Inclusion Criteria}

1. All RTA Patients referred from AE and surgical ward for ophthalmology opinion were included

2. Both males and females were included

3. All age groups were included.

\section{Exclusion Criteria}

1. Ocular injuries due to accidental fall were excluded.

2. Ocular injuries due to assault were not included in study.

3. Injuries due to burns and chemicals were not included.

\section{MATERIALS \& METHODS}

The study was conducted in Government Dharmapuri Medical College Hospital in 2016 for one year among the outpatients and inpatients who had ocular and periocular injuries following Road Traffic Accidents. The following procedures were carried out-

1. Detailed history.

2. Pictorial \& procedural consent.

3. Anterior segment examination with torch light.

4. Slit-lamp examination.

5. Dilatation of pupil \& retinoscopy.

6. Fundus examination using indirect ophthalmoscope or slit-lamp biomicroscope using $78 \mathrm{D}$.

7. CT brain \& CT orbit in selected cases.

Total of 150 Cases examined and the ocular manifestations and the causes of decreased vision analysed. Patients with decreased vision, corneal laceration, iridocyclitis, hyphaema, lens subluxation, optic neuropathy, etc. were meticulously treated and reviewed regularly and again assessed at the end of three months.

\section{RESULTS AND ANALYSIS}

\begin{tabular}{|c|c|c|}
\hline Sex & Numbers & Percentage \\
\hline Male & 128 & $85.33 \%$ \\
\hline Female & 22 & $14.67 \%$ \\
\hline Total & 150 & $100 \%$ \\
\hline \multicolumn{3}{|c|}{ Table 2. Sex Distribution } \\
\hline
\end{tabular}

In the study, males (85.33\%) had more injuries when compared to females (14.67\%). 


\begin{tabular}{|c|c|c|}
\hline Type of Vehicle & No. of Persons & Percentage \\
\hline 2 Wheeler & 131 & $87.33 \%$ \\
\hline 4 Wheeler & 5 & $3.33 \%$ \\
\hline Auto & 8 & $5.33 \%$ \\
\hline Pedestrian & 6 & $4.0 \%$ \\
\hline \multicolumn{2}{|c|}{ Table 3. Mode of Travel while Sustaining RTA } \\
\hline
\end{tabular}

Two wheeler riders $(87.33 \%)$ are more prone to ocular injuries when compared to persons travelling in auto, four wheeler or pedestrians.

\begin{tabular}{|c|c|}
\hline Helmet Wearers & Percentage \\
\hline Present & $8 \%$ \\
\hline Absent & $92 \%$ \\
\hline \multicolumn{2}{|c|}{ Table 4. Helmet Wearing Percentage among } \\
2-Wheeler Riders \\
\hline
\end{tabular}

$92 \%$ of the injured persons did not wear Helmets.

\begin{tabular}{|c|c|}
\hline Alcohol Influence & Percentage \\
\hline Present & $78 \%$ \\
\hline Absent & $22 \%$ \\
\hline \multicolumn{2}{|c|}{ Table 5. Alcohol Influence Among Drivers } \\
\hline
\end{tabular}

Alcohol influence $(78 \%)$ was present in majority of the drivers who sustained ocular Injuries.

\begin{tabular}{|c|c|}
\hline Periorbital ecchymosis & 121 \\
\hline Subconjunctival haemorrhage & 62 \\
\hline Lid laceration & 16 \\
\hline Corneal laceration & 3 \\
\hline Iridocyclitis & 3 \\
\hline Hyphaema & 2 \\
\hline Ruptured globe & 7 \\
\hline Orbital fractures & 14 \\
\hline Lens dislocation & 1 \\
\hline Vitreous haemorrhage & 1 \\
\hline Commotio retinae & 7 \\
\hline Traumatic optic neuropathy & 7 \\
\hline \multicolumn{2}{|c|}{ Table 6. Types of Eye Injuries } \\
\hline \multicolumn{2}{|c|}{}
\end{tabular}

The commonest eye Injuries were Periorbital ecchymoses, Subconjunctival Haemorrhages, lid laceration, Orbital fractures, Ruptured Globe, Commotio Retinae, Traumatic optic neuropathies and Iridocyclitis.

\begin{tabular}{|c|c|}
\hline Lateral wall & 8 \\
\hline Medial wall & 3 \\
\hline Floor & 3 \\
\hline Roof & - \\
\hline \multicolumn{2}{|c|}{ Table 7. Types of Orbital Fractures } \\
\hline
\end{tabular}

In our study, lateral wall fractures are common (8 out of 14) than Medial Wall (3) and Floor (3) of the Orbit.

\begin{tabular}{|c|c|c|}
\hline Type & Numbers & Percentage \\
\hline Closed globe & 143 & $95.34 \%$ \\
\hline Open globe & 7 & $4.67 \%$ \\
\hline \multicolumn{2}{|c|}{ Table 8. Type of Injury } \\
\hline
\end{tabular}

Closed globe injury (95.34\%) more common compared to open globe injury (4.67\%)

\begin{tabular}{|c|c|c|}
\hline Visual Acuity & No. & Percentage \\
\hline $6 / 6$ & 121 & $80.67 \%$ \\
\hline $6 / 9-1 / 18$ & 15 & $10.0 \%$ \\
\hline $6 / 18-3 / 60$ & 9 & $6.0 \%$ \\
\hline $3 / 60-$ NIL & 5 & $3.33 \%$ \\
\hline \multicolumn{2}{|r|}{ Table 9. Visual Assessment after 3 Months } \\
\hline
\end{tabular}

About $20 \%$ of patients with ocular injury had decreased vision and in about $3.3 \%$ of cases the eye sight was lost due to irreparable injury like ruptured globe with prolapsed intraocular contents.

\begin{tabular}{|c|c|c|}
\hline Cause & No. & $\begin{array}{c}\text { Percentage } \\
\text { (Among all Ocular Injuries) }\end{array}$ \\
\hline $\begin{array}{c}\text { Traumatic optic } \\
\text { neuropathy }\end{array}$ & 7 & $4.7 \%$ \\
\hline Commotio retinae & 5 & 3.3 \\
\hline Corneal Laceration & 3 & 2.0 \\
\hline Hyphaema & 2 & 1.33 \\
\hline iridocyclitis & 3 & 2.0 \\
\hline $\begin{array}{c}\text { Lens } \\
\text { (dislocation/traumatic } \\
\text { cataract) }\end{array}$ & 1 & 0.67 \\
\hline Vitreous haemorrhage & 1 & 0.67 \\
\hline Ruptured globe & 7 & 4.7 \\
\hline \multicolumn{2}{|c|}{ Table 10. Causes of Decreased Vision } \\
\hline \multicolumn{2}{|c}{}
\end{tabular}

In the study, common causes for decreased vision associated with ocular injuries are traumatic optic neuropathy, Ruptured globe, Commotio Retinae, Corneal laceration, Iridocyclitis, Hyphaema, Lens dislocation and Vitreous Haemorrhage.

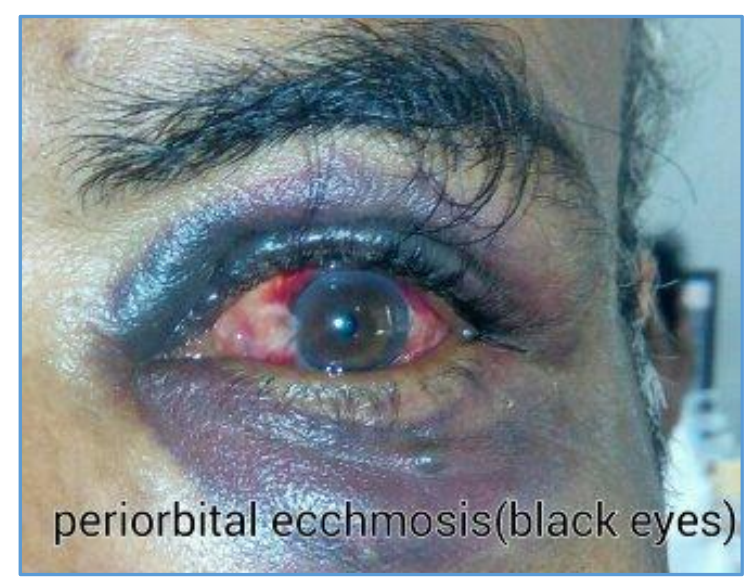

Picture 1. Periorbital Oedema/Contusion/SCH



Picture 2. CT-Fracture of Bony Orbit 


\section{DISCUSSION}

In our study, Males (85.33\%) had more injuries when compared to Females (14.67\%). This is comparable with other studies ${ }^{(4)}$ where $75 \%$ patients were male and $25 \%$ were female.

Regarding distribution based on the Type of Vehicle involved, in our study, two wheeler riders (87.33\%) are more prone to ocular injuries when compared to persons travelling in auto or four wheeler and pedestrians.

In other studies,(5) the maximum number of road traffic accident related injuries was observed in subjects travelling by two wheelers (61.20\%). A total of $36.89 \%$ were travelling by car.

In our study, closed globe injury (95.34\%) was more common compared to open globe injury (4.67\%). In the study done by Avinash Mishra et al, $86.4 \%$ sustained a closed globe injury while $13.6 \%$ had open globe injuries.(6) In another study,(5) integrity of the globe was breached in 10 cases (8.19\%).

In the study, common causes for decreased vision associated with ocular injuries are Traumatic optic neuropathy, Ruptured globe, Commotio Retinae, Corneal laceration, Iridocyclitis, Hyphaema, Lens dislocation and Vitreous Haemorrhage

In other studies also it is stated(4) that Ocular involvement in road traffic accidents may involve the eyelids, lacrimal canaliculi, orbital wall, conjunctiva, cornea, sclera and the extra-ocular muscles. There may be prolapse of uveal tissue, vitreous loss, traumatic cataract, retinal detachment, vitreous haemorrhage, choroidal rupture, optic nerve avulsion or a ruptured globe.

In our study, lateral wall fractures are common (8 out of 14 orbital fracture cases) whereas in literature it is stated that fractures of lateral wall are less common because lateral wall is strong among orbital walls. In our study, lateral wall fractures are common and this may be explained by the fact that major force comes from lateral aspect in many RTAs.

About $20 \%$ of patients with ocular injury had decreased vision and in about $3.3 \%$ of cases the eye sight was lost due to irreparable injury like ruptured globe with prolapsed intraocular contents.

\section{CONCLUSION}

Alcohol, non-safety measures and not following traffic rules are common causes of ocular injuries in RTAs. The fact that the lifetime prevalence of ocular trauma is higher than that of diseases like glaucoma, age-related macular degeneration or diabetic retinopathy (2) shows that vision loss due to ocular trauma can be avoided. This can be accomplished by implementing the traffic rules with strict force and imposing heavy fine and license cancellation for drunken driving.

The fact that appropriate treatment in a tertiary care centre did not significantly influence the final visual outcome makes it imperative that preventive eye care programs for the travelling population is of utmost priority.

Public health education aimed at increasing awareness in the travelling public especially for vulnerable groups and stopping drunken driving is urgently needed in order to reduce ocular morbidity due to ocular trauma.

\section{REFERENCES}

[1] Vats S, Murthy GVS, Chandra M, et al. Epidemiological study of ocular trauma in an urban slum population in Delhi, India. Indian J Ophthalmol 2008;56(4):313-6.

[2] Nirmalan PK, Katz J, Tielsch JM, et al. Ocular trauma in a rural south Indian population: the Aravind comprehensive eye survey. Ophthalmology 2004;111(9):1778-81.

[3] Negussie D, Bejiga A. Ocular emergencies presenting to Menelik II Hospital. Ethiop Med J 2011;49(1):17-24.

[4] El Shtewi M, Shishko MN, Purohit GK. Road traffic accidents and ocular trauma: experience at Tripoli Eye Hospital, Libya. Community Eye Health 1999;12(29):11-2.

[5] Gahlot A, Magdum R, Singh M. A study of ocular trauma profile and its visual outcome in road traffic accidents. National Journal of Medical Research NJMR 2015;5(3):211-5.

[6] Mishra A, Verma AK, Baranwal VK, et al. The pattern and visual outcomes of ocular trauma in a large zonal hospital in a non-operational role: a 36 months retrospective analysis. Journal of Clinical Ophthalmology and Research 2014;2(3):141-4. 